\title{
Pengujian Black Box pada Aplikasi Penghitungan Parkir Swalayan ADA Menggunakan Teknik Equivalence Partitions
}

\section{Bangkit Fajar Nugraha ${ }^{1}$, Fahmi Aditama ${ }^{2}$, Muhammad Arrofi ${ }^{3}$, Solakhul Umam Ahmad ${ }^{4}$, Yulianti Yulianti $^{5}$}

\author{
Teknik Informatika, Universitas Pamulang, Jl. Raya Puspitek No.46, Buaran, Serpong, Tangerang \\ Selatan, Banten, Indonesia, 15310 \\ e-mail: 1bangkitfajar20@gmail.com, ${ }^{2}$ fahmiaditama354@gmail.com, ${ }^{3}$ arrofinita21@gmail.com, \\ 4solakhulumam12@gmail.com, 5yulianti@unpam.ac.id
}

Submitted Date: June $03^{\text {rd }}, 2020$

Revised Date: June $30^{\text {th }}, 2020$
Reviewed Date: June $17^{\text {th }}, 2020$

Accepted Date: June $30^{\text {th }}, 2020$

\begin{abstract}
To ensure that the application (software) Calculation of parking is no error then in need of testing to test the quality of the application. This application has problems with the calculation of the parking in the application, then the application will be tested by the Black Box method based on Equivalence where the application in the overall test is related to the use, benefit, and result of the utilization of such software. The parking application must be error-free, because if there is an error then it will be very detrimental to the self-service that use the parking application, specifically in terms of financial income. The Black Box-based method of Equivalence Partition tests the quality of the application by documenting the software testing which will look at the error in each form, and the errors will be divided into three models, errors, functions, data structures and interfaces. The results of this test, to ensure the quality of the free parking calculation application error by finding an accidental error in the parking calculation application.
\end{abstract}

Keywords: Testing; Software; Black Box; Equivalence Partition

\begin{abstract}
Abstrak
Untuk menjamin aplikasi (software) Penghitungan Parkir yang tidak ada kesalahan maka diperlukan pengujian untuk menguji kualitas aplikasi. Aplikasi ini memiliki masalah pada penghitungan parkir diaplikasi, maka aplikasi akan diuji dengan Metode Black Box berbasis Equivalence di mana aplikasi diuji secara keseluruhan terkait dengan penggunaan, manfaat, dan hasil dari pemanfaatan perangkat lunak tersebut. Aplikasi parkir harus bebas dari kesalahan, karena jika terdapat kesalahan maka hal tersebut akan sangat merugikan pihak swalayan yang menggunakan aplikasi parkir, khususnya dalam hal pemasukan keuangan. Metode Black Box berbasis Equivalence Partition menguji kualitas aplikasi dengan cara melakukan dokumentasi dari pengujian perangkat lunak yang mana akan terlihat kesalahannya pada setiap form, dan kesalahan akan dibagi menjadi tiga model di antaranya, kesalahan fungsi, struktur data dan interface. Hasil dari pengujian ini, untuk menjamin kualitas aplikasi penghitungan parkir bebas dari kesalahan dengan menemukan adanya kesalahan yang tidak disengaja pada aplikasi penghitungan parkir.
\end{abstract}

Kata Kunci: Pengujian; Software; Black Box; Equivalence Partition

\section{Pendahuluan}

Di zaman yang serba modern ini tentu semua hal dalam bidang apapun sangat membutuhkan keakuratan yang mencapai $100 \%$ di mana hal tersebut sangat menentukan dalam hasil yang ingin diperoleh. Termasuk dalam bidang parkiran, tidak banyak yang mengetahui bahwa bidang parkiran di suatu tempat adalah bidang yang sangat membantu dalam hal menambah penghasilan bagi pemilik tempat. Swalayan ADA contohnya, pengunjung yang datang ke swalayan memang tujuan utamanya 
adalah untuk berbelanja, namun hampir rata-rata dari pengunjung pasti membawa kendaraan yang memerlukan tempat parkir untuk memarkir kendaraannya, dengan keadaan tersebut pihak swalayan dapat memanfaatkan lahan yang ada untuk mendapatkan penghasilan tambahan dari biaya parkir kendaraan pengunjung, namun dikarenakan pengunjung yang banyak dan jumlah kendaraan pun banyak, maka sudah tidak memungkin kan lagi untuk menggunakan cara konvensional, dan pihak swalayan memerlukan sebuah aplikasi yang membantu menghitung biaya parkir kendaraan, dengan akurasi penghitungan $100 \%$. Maka dari itu, perlu dilakukannya pengujian terhadap aplikasi parkir yang sudah ada di swalayan, sehingga aplikasi yang digunakan dapat berfungsi sesuai dengan fungsinya dan juga semua tools yang ada di dalam aplikasi parkir berjalan dengan semestinya.

Aplikasi penghitungan parkir merupakan cara penghitungan untuk menentukan Biaya parkir dari sebuah kendaraan yang masuk ke wilayah parkiran swalayan ADA. Jadi, Sistem yang dikembangkan bertujuan untuk menghasilkan penghitungan terhadap biaya parkiran, yang akurat serta dengan proses yang cepat dan mudah digunakan. Dalam aplikasi penghitungan parkir ini terdapat 2 proses yang dilakukan yaitu, proses memasukkan kendaraan saat memasuki parkiran, dan proses kendaraan keluar parkiran, di mana diproses parkir masuk, user harus memasukkan nomer polisi dan jenis kendaraan yang akan masuk ke wilayah parkiran, dan data kendaraan tersebut akan masuk ke database. Dan diproses parkir keluar, terdapat proses mencari nomor polisi yang sudah ada di dalam database yang sebelumnya dimasukkan di dalam proses parkir masuk, lalu secara otomatis keluar biaya yang harus dibayar dan berapa lama waktu parkir.

Pada aplikasi penghitungan parkir terdapat kesalahan pada saat proses keluar kendaraan, kendaraan yang sudah keluar tidak terhapus dari database dan waktu yang muncul tidak sesuai dengan waktu realtime saat ini sehingga merugikan pihak swalayan dalam penghitungan biaya parkir. Maka, aplikasi ini perlu dilakukan pengujian agar kesalahan yang tidak disengaja dapat ditemukan, dan aplikasi ini dapat berjalan sesuai dengan fungsinya, sehingga lebih meminimalisir kesalahan dalam penghitungan biaya, sehingga tidak memunculkan kerugian bagi pengguna aplikasi parkir ini.
Untuk menjamin aplikasi penghitungan parkir tidak ada kesalahan maka, aplikasi ini perlu diuji agar kesalahn yang tidak disengaja dapat ditemukan. Tujuan dari pengujian adalah untuk memastikan bahwa aplikasi yang dihasilkan sesuai dengan kebutuhan dan layak untuk digunakan (Arwaz, Putra, Putra, Kusumawijaya, \& Saifudin, 2019).

Pengujian ini akan menggunakan metode pengujian Black Box yang memiliki arti bahwa pengujian ini hanya memeriksa suatu perangkat lunak dari hasil yang sudah dieksekusi, tanpa harus tau lebih detail ke dalam source dari perangkat lunak tersebut, dengan kata lain, bahwa kita hanya melihat secara fungsionalnya saja apakah sudah berfungsi sesuai dengan fungsinya. Black Box adalah teknik pengujian yang berfokus pada spesifikasi fungsional dari perangkat lunak, penguji dapat mendefinisikan kumpulan kondisi masukan dan melakukan pengetesan pada spesifikasi fungsional program (Hidayat \& Muttaqin, 2018). Black Box hanya mengevaluasi bagian dari tampilan antarmuka (interface) dan fungsional tanpa mengetahui apa yang terjadi dalam proses detailnya yang berarti bahwa hanya dapat mengetahui masukan dan keluaran saja, maka dilakukan langkah pemeriksaan untuk memastikan bahwa data tersebut telah sesuai dengan yang ditetapkan dan bertujuan untuk memastikan bahwa data akan dimasukkan ke dalam basis data itu telah diketahui dan dapat dijelaskan kebenaran datanya (MZ, 2016).

Black Box Testing bukanlah solusi alternatif dari White Box Testing tapi lebih sebagai pelengkap untuk menguji hal-hal yang tidak dicakup oleh White Box Testing. Black Box Testing mengidentifikasi jenis kesalahan dalam beberapa kategori antara lain fungsi yang tidak benar atau tidak ada, kesalahan antarmuka (interface errors), kesalahan pada struktur data dan akses basis data, kesalahan performansi (performance errors) dan kesalahan inisialisasi maupun terminasi (Mustaqbal, Firdaus, \& Rahmadi, 2015).

Metode Equivalence Partitions adalah metode dari tekhnik pengujian Blackbox dengan cara domain masukan dari suatu program dipecah atau dibagi ke dalam kelas-kelas data agar memperoleh Test Case. Perancangan Test Case Equivalence Partitions didapat dari evaluasi kelas Equivalence yang menggambarkan kondisi masukan, kumpulan kadaan yang valid atau tidak. Kondisi masukan biasanya berupa nilai numeric, range nilai, dan kumpulan nilai-nilai yang 
berhubungan dengan kondisi Boolean. Semua tahapan akan dibahas pada pembahasan selanjutnya.

\section{Metodologi}

Pengujian adalah hal yang harus dilakukan seorang programer untuk menghasilkan perangkat lunak yang dibangun bebas dari kesalahan dan semakin berkualitas. Pengujian perangkat lunak merupakan sebuah proses pengujian program yang dimaksudkan untuk mencari kesalahan pada software dan memperbaikinya sehingga memiliki kualitas yang baik (Febrian, Ramadhan, Faisal, \& Saifudin, 2020). Melalui pengujian, seorang programer dapat mengetahui kekurangan dan kesalahan yang terdapat di dalam sebuah sistem sehingga dapat segera memperbaikinya. Tujuannya adalah menyesuaikan fungsi-fungsi dengan spesifikasi yang diinginkan (Andriansyah, 2018).

Pengujian software sangat diperlukan untuk memastikan apakah aplikasi (software) yang sedang dibuat bebas dari kesalahan dan berjalan sesuai yang diharapkan. Pengujian harus dilakukan secara teliti dan lengkap, karena jika pengujian yang dilakukan tidak lengkap dan efektif dapat menimbulkan masalah dan menyebabkan kerugian ketika software digunakan (Rosalina, Rassi, Hadi, Ubaidillah, \& Desyani, 2020). Penguji software harus menyiapkan sesi khusus untuk menguji program yang sudah dibuat agar kesalahan ataupun kekurangan dapat dideteksi sejak awal dan dikoreksi secepatnya. (Shi, 2010).

Pengujian Black Box bertujuan menemukan klasifikasi kesalahan dalam beberapa kategori, yaitu fungsi-fungsi yang salah atau hilang, kesalahan interface, kesalahan dalam struktur data atau akses database eksternal, kesalahan performa, kesalahan dan terminasi (Agarwal, Tayal, \& Gupta, 2010). Dalam pengujian Black Box Testing digunakan alat untuk pengumpulan data yang disebut dengan user acceptance test, dokumen ini terdiri deskripsi indikator dari prosedur pengujian fungsionalitas dari perangkat lunak. Dengan metode Black Box Testing ini, pengembang perangkat lunak parkiran ini dapat menguji keseluruhan fitur atau menu yang terdapat pada sistem tersebut (Setiyani, 2019). Metode Equivalence Partitions merupakan pengujian berdasarkan masukan setiap menu yang terdapat pada sistem Aplikasi Parkir di setiap menu masukan dilakukan pengujian memalui klasisifikasi dan pengelompokan berdasarkan fungsinya (Hidayat \& Muttaqin, 2018).

Penelitian ini akan dilakukan beberapa tahapan. Pada tahapan pertama diawali dengan menentukan Test Case perangkat lunak yang akan diuji dengan metode Equivalence Partitions kemudian menginisialisasi standar grade partition masukan dan keluaran. Hal ini dilakukan untuk mendapatkan dataset berupa dokumentasi pengujian dengan metode Equivalence Partitions dan nilai tingkat efektifitas metode Equivalence Partitions.

Berdasarkan form dan teknik pengujian Black Box dibuat tabel rancangan Test Case yang berfungsi untuk menyimpulkan apakah sistem berhasil dalam pengujian tipe tersebut atau tidak. Berikut terdapat penjelasan dari beberapa tabel Rancangan Test Case berdasarkan Equivalence Partition.

Pada form pada Gambar 1 terdapat beberapa rencana pengujian. Rencana pengujian no polisi data akan valid jika ID diisi dengan memasukkan kombinasi alfabet dan angka "B 23476 TU" yang terdiri dari maksimal 15 digit dan tidak boleh kosong. Sebaliknya, data tidak valid jika memasukkan hanya abjad atau angka saja. Pada rencana pengujian Jenis kendaraan data akan valid jika Jenis dipilih salah satu dari jenis kendaraan yang sudah ada. Sebaliknya, data tidak valid jika field jenis kendaraan tidak dipilih, dan akan muncul catatan "harap pilih jenis kendaraan" dan Pada saat user klik tombol simpan, nomor polisi yang sudah dimasukkan akan masuk ke database dan akan ditampilkan pada tabel, dan akan muncul tanggal masuk pada tabel, tanggal masuk sesuai dengan tanggal realtime pada saat kendaraan masuk.

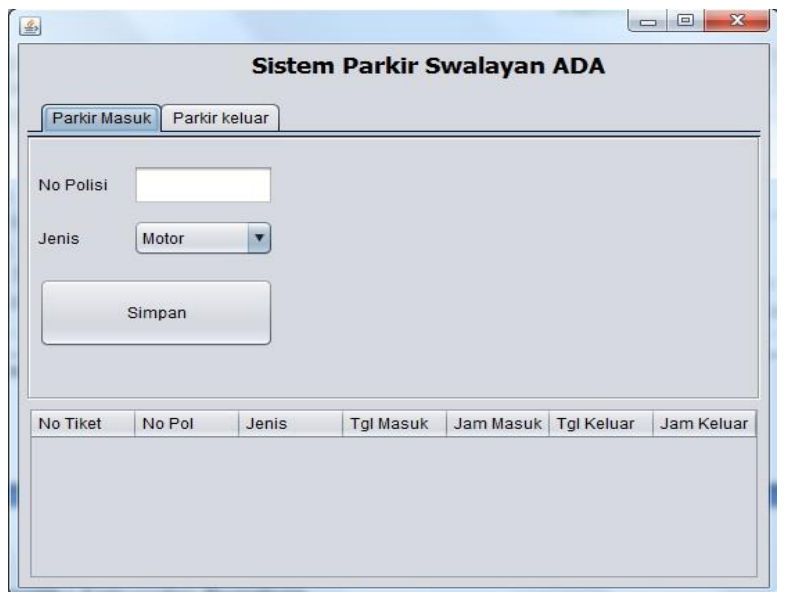

Gambar 1. Form parkir masuk 
Tabel 1. Rancangan Test Case Form Parkir Masuk

\begin{tabular}{|l|l|l|}
\hline Id & \multicolumn{1}{|c|}{ Deskripsi Pengujian } & \multicolumn{1}{|c|}{ Hasil yang Diharapkan } \\
\hline PM 01 & $\begin{array}{l}\text { Mengisi No Polisi dengan "B 23476 TU", } \\
\text { Dan pilih jenis kendaraan dengan "Motor" } \\
\text { kemudian klik tombol "Simpan" }\end{array}$ & $\begin{array}{l}\text { Sistem berhasil menerima penambahan } \\
\text { Data, dan muncul Tanggal masuk sesuai dengan } \\
\text { Tanggal Realtime }\end{array}$ \\
\hline PM 02 & $\begin{array}{l}\text { Mengisi No Polisi dengan "123" atau tidak } \\
\text { diisi, dan jenis tidak dipilih kemudian klik } \\
\text { tombol Daftar }\end{array}$ & $\begin{array}{l}\text { Sistem menolak untuk menyimpan data dan } \\
\text { muncul notifikasi }\end{array}$ \\
\hline
\end{tabular}

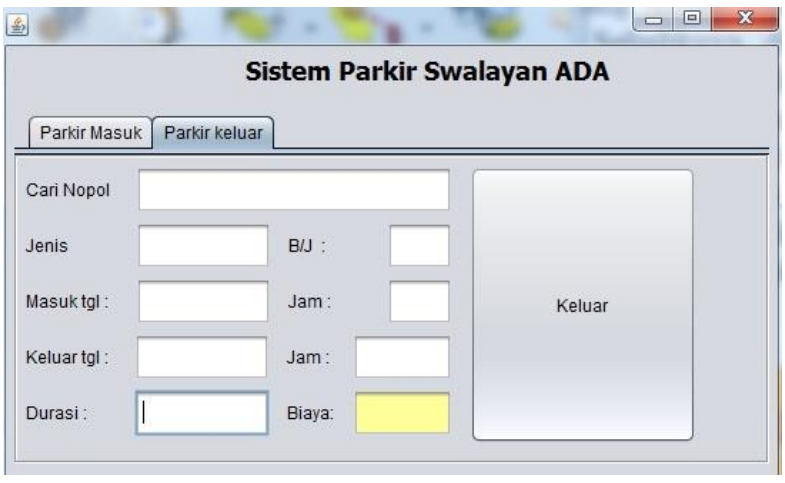

Gambar 2. Form Parkir Keluar

Pada form pada Gambar 2 terdapat beberapa rencana pengujian. Rencana pengujian cari nopol data akan valid jika nopol yang dicari sudah dimasukkan pada form Parkir masuk dan tidak boleh kosong. Setelah memasukkan data pencarian nopol selesai dan ditekan enter, maka akan Muncul Jenis kendaraan, Tanggal Masuk, dan jam masuk, sesuai dengan yang sudah dimasukkan di form parkir masuk. Ketika user klik tombol keluar, maka sistem akan memproses data kendaraan keluar, dan dihapus dari database, akan muncul jam keluar dan tanggal keluar sesuai dengan Tanggal realtime, biaya pun akan dihitung secara otomati dari penghitungan waktu masuk sampai dengan waktu keluar. Sebaliknya data tidak akan valid jika field Cari nopol kosong atau nomer polisi belum dimasukkan pada form parkir masuk, dan akan muncul notifikasi "Data tidak ditemukan". Jika Field cari nopol masih kosong tombol keluar pun tidak akan berfungsi untuk memproses hapus data dari database, dan menghitung biaya parkir yang harus dibayarkan.

Tabel 2. Rancangan Test Case Form Parkir Keluar

\begin{tabular}{|l|l|l|}
\hline Id & \multicolumn{1}{|c|}{ Deskripsi Pengujian } & \multicolumn{1}{|c|}{ Hasil yang Diharapkan } \\
\hline PK 01 & $\begin{array}{l}\text { Mengisi Cari nopol dengan memasukkan nomor } \\
\text { polisi "B 23476 TU" sesuai dengan nomor polisi } \\
\text { pada form parkir masuk, dan enter }\end{array}$ & $\begin{array}{l}\text { Sistem mampu Menampilkan Jenis } \\
\text { kendaraan, Tanggal masuk, dan jam } \\
\text { Masuk }\end{array}$ \\
\hline PK 02 & $\begin{array}{l}\text { Klik Tombol "Keluar" setelah nomor polisi yang } \\
\text { dimasukkan sesuai dengan nomor polisi yang } \\
\text { dimasukkan di form parkir masuk }\end{array}$ & $\begin{array}{l}\text { Sistem mampu memproses data } \\
\text { kendaraan dihapus dari database, dan } \\
\text { menampilkan Jam keluar, durasi, dan } \\
\text { biaya parkir }\end{array}$ \\
\hline PK 03 & $\begin{array}{l}\text { Mengisi Cari nopol dengan "123" tidak sesuai } \\
\text { dengan nomor polisi pada form parkir masuk, atau } \\
\text { tidak diisi sama sekali,dan enter }\end{array}$ & $\begin{array}{l}\text { Sistem menolak menampilkan data } \\
\text { dan muncul noti "data tidak ada" }\end{array}$ \\
\hline PK 04 & $\begin{array}{l}\text { Klik Tombol "Keluar" saat nopol yang } \\
\text { dimasukkan salah atau tidak diisi }\end{array}$ & Sistem menolak memproses data \\
\hline
\end{tabular}

\section{Hasil dan Pembahasan}

Berdasarkan rencana pengujian yang telah disusun, dan direncanakan maka dapat dilakukan pengujian sebagai berikut: 
Tabel 3. Hasil Pengujian

\begin{tabular}{|c|c|c|c|c|}
\hline Id & Deskripsi Pengujian & Hasil yang diharapkan & Hasil Pengujian & Kesimpulan \\
\hline K1 & $\begin{array}{l}\text { Mengisi No Polisi } \\
\text { dengan "B } 23476 \\
\text { TU", Dan pilih jenis } \\
\text { kendaraan dengan } \\
\text { "Motor" kemudian } \\
\text { klik tombol "Simpan" }\end{array}$ & $\begin{array}{l}\text { Sistem berhasil menerima } \\
\text { penambahan data, dan } \\
\text { muncul Tanggal masuk } \\
\text { sesuai dengan Tanggal } \\
\text { Realtime }\end{array}$ & $\begin{array}{l}\text { Tampil Pop Up data } \\
\text { Berhasil disimpan, } \\
\text { dan lanjut untuk } \\
\text { memasukkan nopol } \\
\text { selanjutnya }\end{array}$ & Tidak sesuai \\
\hline K2 & $\begin{array}{l}\text { Mengisi No Polisi } \\
\text { dengan " } 123 \text { " atau } \\
\text { tidak diisi }\end{array}$ & $\begin{array}{l}\text { Sistem menolak untuk } \\
\text { menyimpan data dan } \\
\text { muncul notifikasi }\end{array}$ & $\begin{array}{l}\text { Tampilan muncul } \\
\text { notifikasi "data tidak } \\
\text { sesuai" }\end{array}$ & Sesuai \\
\hline K3 & $\begin{array}{l}\text { Mengisi Cari nopol } \\
\text { dengan “B } 23476 \\
\text { TU”,dan enter }\end{array}$ & $\begin{array}{l}\text { Sistem mampu } \\
\text { Menampilkan Jenis } \\
\text { kendaraan, Tanggal } \\
\text { masuk, dan jam Masuk }\end{array}$ & $\begin{array}{l}\text { Sistem mampu } \\
\text { Menampilkan Jenis } \\
\text { kendaraan, Tanggal } \\
\text { masuk, dan jam } \\
\text { Masuk }\end{array}$ & Sesuai \\
\hline $\mathrm{K} 4$ & $\begin{array}{l}\text { Klik Tombol } \\
\text { "Keluar" setelah } \\
\text { nomor polisi yang } \\
\text { dimasukkan sesuai } \\
\text { dengan nomor polisi } \\
\text { yang dimasukkan di } \\
\text { form parkir masuk }\end{array}$ & $\begin{array}{l}\text { Sistem mampu } \\
\text { memproses data } \\
\text { kendaraan dihapus dari } \\
\text { database, dan } \\
\text { menampilkan Jam } \\
\text { keluar, durasi, dan biaya } \\
\text { parkir }\end{array}$ & $\begin{array}{l}\text { Sistem mampu } \\
\text { memproses data } \\
\text { kendaraan dihapus } \\
\text { dari database, dan } \\
\text { menampilkan jam } \\
\text { keluar, namun durasi, } \\
\text { dan biaya parkir tidak } \\
\text { muncul }\end{array}$ & Tidak Sesuai \\
\hline K5 & $\begin{array}{l}\text { Mengisi Cari nopol } \\
\text { dengan " } 123 \text { ",atau } \\
\text { tidak diisi,dan enter }\end{array}$ & $\begin{array}{l}\text { Sistem menolak } \\
\text { menampilkan data dan } \\
\text { muncul noti "data tidak } \\
\text { ada" }\end{array}$ & $\begin{array}{l}\text { Sistem menolak } \\
\text { menampilkan data } \\
\text { dan muncul noti "data } \\
\text { tidak ada" }\end{array}$ & Sesuai \\
\hline K6 & $\begin{array}{l}\text { Klik Tombol } \\
\text { "Keluar" saat nopol } \\
\text { yang dimasukkan } \\
\text { salah atau tidak diisi } \\
\end{array}$ & $\begin{array}{l}\text { Sistem menolak } \\
\text { memproses data }\end{array}$ & $\begin{array}{l}\text { Sistem menolak } \\
\text { memproses data }\end{array}$ & Sesuai \\
\hline
\end{tabular}

Terdapat 2 Jumlah Form yang diuji dengan form Parkir masuk diuji sebanyak 2 kali, form parkir keluar diuji sebanyak 4 kali, sehingga total pengujian dilakukan 6 kali. Jumlah form yang ditemukan eror sebanyak 1 eror yang ada di form parkir masuk, dan 1 eror ditemukan di form parkir keluar.

\section{Kesimpulan}

Pengujian perangkat lunak dengan menggunakan metode Black Box dapat menghasilkan pengujian yang menentukan perangkat lunak yang diuji apakah dapat berjalan dengan yang sesuai diharapkan atau tidak. Berdasarkan pengujian kualitas aplikasi penghitungan parkir, dapat diambil kesimpulan bahwa pengujian dengan metode Black Box berbasis Equivalence Partitions dapat membantu proses pembuatan case pengujian, uji kualitas dan menemukan kesalahan yang tidak disengaja. Dalam pengujian aplikasi penghitungan parkir ditemukan kesalahan dalam pengaturan (setting) waktu, sehingga hal tersebut menyebabkan proses penghitungan biaya parkir tidak berjalan dengan semestinya. Hal ini dapat segera diperbaiki agar aplikasi berjalan dengan baik.

\section{Saran}

Berdasarkan proses pengujian kualitas aplikasi penghitungan parkir, penulis memberikan saran pada penelitian selanjutnya untuk mempelajari dengan sungguh-sungguh metode yang akan digunakan dalam pelaksanaan penelitian, dengan cara mencari refrensi dari sumber-sumber yang terkait, sehingga penelitian yang akan dilakukan dapat berjalan dengan baik dan hasilnya pun sesuai dengan yang diharapkan. 


\section{References}

Agarwal, B., Tayal, S. P., \& Gupta, M. (2010). Software Engineering \& Testing. Boston: AuthorJones \& Bartlett Learning.

Andriansyah, D. (2018). Pengujian Kotak Hitam Boundary Value Analysis Pada Sistem Informasi Manajemen Konseling Tugas Akhir. STMIK Nusa Mandiri Jakarta. Indonesia Journal on Networking and Security, 7(1), 1318.

Arwaz, A. A., Putra, K., Putra, R., Kusumawijaya, T., \& Saifudin, A. (2019). Pengujian Black Box pada Aplikasi Sistem Seleksi Pemenang Tender Menggunakan Teknik Equivalence Partitions. Jurnal Teknologi Sistem Informasi dan Aplikasi, 2(4), 130-134. doi:10.32493/jtsi.v2i4.3708

Febrian, V., Ramadhan, M. R., Faisal, M., \& Saifudin, A. (2020). Pengujian pada Aplikasi Penggajian Pegawai dengan menggunakan Metode Blackbox. Jurnal Informatika Universitas Pamulang, 5(1), 61-66. doi:10.32493/informatika.v5i1.4340

Hidayat, T., \& Muttaqin, M. (2018). Pengujian Sistem Informasi Pendaftaran dan Pembayaran Wisuda Online menggunakan Black Box Testing dengan Metode Equivalence
Partitioning dan Boundary Value Analysis. Jurnal Teknik Informatika UNIS, 6(1), 25-29.

MZ, M. M. K. (2016). Pengujian Perangkat Lunak Metode Black Box Berbasis Equivalence Partitions Pada Aplikasi Sistem Informasi Sekolah. Jurnal Mikrotik, 6(3), 1-8.

Mustaqbal, M., Firdaus, R., \& Rahmadi, H. (2015). engujian Aplikasi Menggunakan Black Box Testing Boundary Value Analysis (Studi Kasus: Aplikasi Prediksi Kelulusan SNMPTN). Jurnal Ilmiah Teknologi Informasi Terapan, 1(3), 31-36.

Rosalina, A., Rassi, A. A., Hadi, G. Y., Ubaidillah, R., \& Desyani, T. (2020). Pengujian Black Box pada Sistem Informasi Penjualan HI Shoe Store Menggunakan Teknik Equivalence Partitions. Jurnal Informatika Universitas Pamulang, 5, 26-29. doi:10.32493/informatika.v5i1.3964

Setiyani, L. (2019). Pengujian Sistem Informasi Inventory Pada Perusahaan Distributor Farmasi Menggunakan Metode Black Box Testing. Jurnal Ilmu Komputer \& Teknologi Informasi, 4(1), 1-9.

Shi, M. (2010). Software Functional Testing from the Perspective of Business Practice. Computer and Information Science, 3(4), 49 - 52. 